\title{
Value-Growth Timing: Evidence From The Johannesburg Stock Exchange
}

\author{
Kathleen Hodnett, PhD, University of the Western Cape, South Africa
}

\begin{abstract}
This study attempts to establish the cyclical nature of the value-growth spread on the Johannesburg Stock Exchange (JSE) over the period from 1 January 1997 through 31 December 2013, and subsequently undertakes to determine if the recent value-growth spread could be useful to forecast the near-term market risk premium. The three relative valuation benchmarks used to classify value and growth stocks include earnings/price ratio (E/P), book/price ratio (B/P) and sales/price ratio $(S / P)$. The ratio between the median $S / P$ ratio for the value portfolio versus the growth portfolio is found to be the highest and most volatile over the examination period, which suggests that the relative valuation of value and growth stocks based on $S / P$ could be cyclical and reflective of the market sentiments and degrees of risk aversion. The prediction of forward market risk premium using the trailing average of $S / P$ value-growth spread achieved the highest $R$ squared of $26.79 \%$. In addition, predicting forward market risk premium using the other two value-growth spreads is also statistically significant. Examining the coefficients of the regressions reveals that although a significant portion of the forward market risk premium is left unexplained, there exists a significantly positive correlation between recent value-growth spreads and nearterm market risk premiums on the JSE. This implies that higher future reward could be expected for equity investments when the value risk premium is higher than its historical average, and vice versa.
\end{abstract}

Keywords: Value-Growth Spread; Johannesburg Stock Exchange (JSE)

\section{INTRODUCTION}

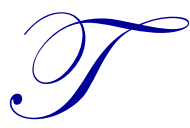

he value risk premium, introduced by Fama and French (1993) refers to the excess return of value stocks over growth stocks, where the book/price multiple is used as the relative valuation benchmark. Since the future prospects of the firms are reflected in the prices of their stocks, one would expect firms with ample growth opportunities to trade at lower book/price ratio compared to value stocks. According to Fama and French (1993), it is necessary to incorporate the value risk premium in the asset pricing model since investors are required to be compensated for investing in value stocks which are perceived to be riskier. Besides the book/price multiple, other attributes that are frequently used to test the premium of value stocks versus growth stocks include various fundamental value-to-price multiples such as earnings/price (i.e. earnings yield), sales/price, dividend/price (i.e. dividend yield) to name a few.

Although empirical evidence supports the outperformance of value over growth stocks in the long term, value investing is risky in that it could produce prolonged periods of poor performance. According to Asness, Friedman, Krail and Liew (2000), the value risk premium could be cyclical due to rational factors or irrational factors. Rational factors could be either varying risk of value versus growth stocks through time or varying required compensation for value over growth stocks. Irrational factors, on the other hand, refer to mispricing of value versus growth stocks and the varying degrees of mispricing through time. If the return difference between value stocks and growth stocks, known as the value-growth spread are cyclical over time, pricing assets using models that incorporate the value risk premium would be inconsistent over time. This implies that there are merits for value-growth rotation in the equity markets. In addition, if the cyclical nature of the value-growth spread is related to the investor sentiments and degrees of risk aversion based on the future prospects of the market, it could be used as a tool to forecast the future directions of the market. 
This study examines the cyclical nature of the value-growth spread on the JSE based on the three relative valuation benchmarks studies by Asness et al. (2000), namely earning/price (E/P) ratio, book/price (B/P) ratio and sales/price (S/P) ratio. These attributes are found to receive significant positive payoffs on the JSE Limited in Hodnett, Hsieh and van Rensburg (2012) over the period from 1997 through 2007. The study attempts to establish whether recent performance of the E/P, B/P and S/P value-growth spreads could be used to forecast the near-term market risk premium on the JSE.

\section{LITERATURE REVIEW}

Beckers and Thomas (2010) argue that compensations to style risk premiums are cyclical through bull and bear phases of the markets, similar to defensive and cyclical sectors having varying performances across different economic regimes. Thus, an ability to forecast the turning points of investment styles would contribute to better portfolio performance. Kao and Shumaker (1999) evaluate the benefits of equity timing strategies in the U.S. equity markets over the period from January 1979 through June 1997. The monthly seasonality for the value-growth spread is identified as the value risk premium and is significantly positive in January and March and yet significantly negative in November when the size effect is controlled for. The examination of the serial correlation of the timeseries value-growth spread reveals that there exists a mild positive correlation between prior 1-month spread and the 1-month forward spread for both large and small cap stocks. In addition, a mild negative correlation is also identified for the trailing and forward 12-month spreads for small cap stocks. The authors also examine the relative explanatory power of macroeconomic variables in predicting the forward rolling 12-month value-growth spread. Study results suggest that the earnings yield gap, calculated as the difference between the earnings yield of the market proxy and the long-term bond yield exhibited significantly negative correlation with the value-growth spread. The forward value-growth spread also exhibits some degrees of positive correlation with yield curve spread, real bond yield and estimated GDP growth.

Asness, Friedman, Krail and Liew (2000) propose that the relative price multiples between the value and growth portfolios and the relative expected earnings growth between the value and growth portfolios could be used to forecast the near future value-growth spread. These factors are also supported by the Gordon's dividend growth model. Asness et al. (2000) forecast the rolling 12-month value-growth spread in the U.S. stock markets over the period from 1982 to 1999 using the ratio between the median book/price, earnings/price and sales/price for the value and growth portfolio in conjunction with the relative earnings growth between the value and growth portfolio. The regression results indicate that future value-growth spread is predictable with $38.7 \%$ adjusted R-square. Lucas, van Dijk and Kloek (2002) investigated the timing variation of payoffs to style attributes in the U.S. stock markets over the period from June 1984 to July 1999. Various models of style-dependent strategies were devised and tested. Their results show that business cycle oriented techniques produce superior risk-adjusted performance to pure statistical models that are less robust.

The cyclical nature of the value risk premiums are not found by Athanassakos (2009), who exams the value risk premium in the Canadian Stock Exchange over the period from 1985 to 2005 using price/book ratio and price/earnings ratio as the value-growth benchmarks. The study documents strong evidence of a pervasive value effect across industries and during all phases of the economic cycle over the examination period. More importantly, study results indicate that the value risk premiums are not accrued to only few outliers, but pervasive for the overwhelming majority of the value stocks in the testing sample. On the other hand, Beckers and Thomas (2010) finds that despite the fact that the returns for various investment styles such as momentum, earnings variation and leverage are found to be cyclical, the returns for value stocks and growth stocks are not significantly different during expansionary and recessionary phases of the economic cycle in U.S. (from February 1973 to December 2008), Europe (from January 1997 to December 2008) and Japan (from December 1984 to December 2008) respectively.

In South Africa, Graham and Uliana (2001) test for evidence of the value-growth phenomenon on the Johannesburg Stock Exchange over the period from 1987 to 1996. The study reveals that growth stocks earn superior returns to value stocks in the late 1980s and early 1990s. Significant outperformance of value stocks over growth stocks is found thereafter. The authors attribute the cyclical findings of the value-growth spread to changes in the political regime in the early 1990s and the double-digit inflation hikes over the period from 1987 to 1992. Mutooni and Muller (2007) test the profitability of style timing strategies on the JSE over the period from 1986 
through 2006. Study results reveal that although value stocks are found to outperform growth stocks over the examination period, the outperformance is found to be cyclical with value stocks outperformed by growth stocks occasionally. When term structure, co-incident indicator and earnings yield gap are used to determine the turning points for the style rotation strategy, significant outperformance is identified over a buy-and-hold strategy in either value or growth portfolios.

\section{EMPIRICAL TESTS}

\section{Research Data}

This study aims to establish the cyclical nature of the value risk premiums on the JSE over the examination period from 01 January 2004 to 31 December 2013 with the attempt to forecast the forward market risk premium using historical value risk premiums. Fama and French (1993) use the return difference (spread) between stocks with high book-to-market value ratio and stocks with low book-to-market value ratio as the proxy for the value risk premium. In this study, the three ratios examined by Asness et al. (2000), namely earnings-to-price ratio (E/P), book-to-price ratio $(\mathrm{B} / \mathrm{P})$ and sales-to-price ratio $(\mathrm{S} / \mathrm{P})$ are used as benchmarks to classify value stocks and growth stocks. The value risk premiums are proxied by the spreads between value portfolio returns and growth portfolio returns based on the respective value-growth benchmarks.

Companies comprising the FTSE/JSE ALL Share Index (ALSI) in any given point in time over the examination period were included in the research sample. Sample shares that were delisted or suspended during the examination period are included in the sample until their respective delisting or suspension dates. It is crucial that the research sample does not exhibit survivorship bias, especially for studies concerning contrarian investing strategies. This is because contrarian stocks are more likely to be non-survivors and exclusion of delisted or suspended shares may create an upward bias for contrarian portfolios. The monthly closing prices, market capitalization, total earnings after tax, book value of ordinary equity and sales were downloaded from the Stockground database hosted by INET BFA. South African firms have various financial year ends and Stockground records interim financial statement results in April and final financial statement results in October. In order to avoid the look-ahead bias, the financial year ends of sample firms were extracted with earnings after tax, book value and sales data of sample shares to be rearranged to ensure that the data is recorded with a 3-month delay since the interim and financial year end of the sample shares. In addition, interim income statement items such as earnings after tax and sales are converted to annual data by including the records in the second half of the previous financial year.

\section{Relative Valuation Benchmarks}

At the beginning of each month over the examination period, sample stocks are allocated into the value stock quintile or growth stock quintile based on their E/P, B/P and S/P ratios respectively. Stocks in the quintile with the highest $\mathrm{E} / \mathrm{P}, \mathrm{B} / \mathrm{P}$ and $\mathrm{S} / \mathrm{P}$ ratios are classified as value stocks; and stocks in the lowest $\mathrm{E} / \mathrm{P}, \mathrm{B} / \mathrm{P}$ and $\mathrm{S} / \mathrm{P}$ quintiles are classified as growth stocks. Thus, three monthly-rebalanced value and three growth portfolios are formed based on the E/P, B/P and S/P ratios of the sample stocks in the monthly cross-section. The E/P, B/P or S/P ratios of sample stocks at the beginning of month $t$ (i.e. month $t-1$ ) are computed using Equation 1.

$$
(\text { Attribute } / \text { Price })_{i, B e g, t}=A_{i, t-1} / \text { Cap }_{i, t-1}
$$

Where:

$A_{i, t-1} \quad$ is firm $i$ 's latest available total earnings after tax, book value or sales at the beginning of month $t$; and $\mathrm{Cap}_{i, t-1}$ is firm $i$ 's market capitalization at the beginning of month $t$. 


\section{Relative Valuation Between The Value-Growth Benchmarks}

Once the sample stocks are categorized into the value $(V)$ or growth $(G)$ quintile for each of the relative valuation benchmarks, the median values of the $\mathrm{E} / \mathrm{P}, \mathrm{B} / \mathrm{P}$ and $\mathrm{S} / \mathrm{P}$ relative valuation benchmarks are computed for the value and growth portfolios respectively at the beginning of each month over the examination period. The ratio between the median $\mathrm{E} / \mathrm{P}, \mathrm{B} / \mathrm{P}$ or $\mathrm{S} / \mathrm{P}$ of the value portfolio versus the median $\mathrm{E} / \mathrm{P}, \mathrm{B} / \mathrm{P}$ or $\mathrm{S} / \mathrm{P}$ of the growth portfolio is termed the median value-growth ratios. The summary statistics for the median value-growth ratios for each of the three relative valuation benchmarks are presented in Table 1 . The historical averages and dispersions of the monthly median value-growth ratios provide indications of the relative consistency in the valuation of value versus growth stocks based on different relative valuation benchmarks. The average median S/P ratio of 1.47 times is the highest amongst the three median value-growth ratios. The median $\mathrm{S} / \mathrm{P}$ ratio is also the most volatile median value-growth ratio over the examination period with the maximum value of 1.68 times and the minimum value of 1.27 times. This result is similar to the findings of Asness et al. (2000). These characteristics implies that the S/P ratios are relatively more sensitive to changes in market condition or investor sentiments, which translates to varying valuations for value and growth stocks based on the S/P ratio over the examination period. On the other hand, although the median $\mathrm{E} / \mathrm{P}$ ratio of 1.22 is the lowest amongst the three median value-growth ratios, it is the most stable valuation metric with the lowest standard deviation of $6.84 \%$.

Table 1: Summary Statistics For Median Value-Growth Ratios

\begin{tabular}{lccc}
\hline & $\begin{array}{c}\text { Median Earnings/Price } \\
\text { Value: Growth }\end{array}$ & $\begin{array}{c}\text { Median Book/Price } \\
\text { Value: Growth }\end{array}$ & $\begin{array}{c}\text { Median Sales/Price } \\
\text { Value: Growth }\end{array}$ \\
\hline Average & 1.22 times & 1.33 times & 1.47 times \\
\hline Standard Deviation & $6.84 \%$ & $7.88 \% \%$ & $9.70 \%$ \\
\hline Maximum & 1.40 times & 1.52 times & 1.68 times \\
\hline Minimum & 1.08 times & 1.18 times & 1.27 times \\
\hline
\end{tabular}

\section{Characteristics Of The Value Risk Premiums (Value-Growth Spread)}

The value risk premium is calculated as the return difference between the value portfolio and the growth portfolio. The equally-weighted portfolio returns for the value $(V)$ or growth $(G)$ quintile in month $t$ is computed using Equation 2.

$R_{V \text { or } G, t}=\sum_{j=1}^{N} r_{j, V \text { or } G, t} / N_{t-1}$

The total return for the $j t h$ constituent in the value $(V)$ or growth $(G)$ quintile in month $t$, is computed by including the dividend payment $(D)$ in month $t$ as demonstrated in Equation 3.

$r_{j, V \text { or } G, t}=\left(\right.$ Price $\left._{j, V \text { or } G, t}+D_{j, V \text { or } G, t}\right) /$ Price $_{j, V \text { or } G, t-1}$

Where:

$r_{j, V \text { or } G, t}$ is the $j t h$ constituent total return in the value $(V)$ or growth $(G)$ quintile for month $t$; and

$N_{t-1} \quad$ is the number of constituents in the value $(V)$ or growth $(G)$ quintile at the beginning of month $t$.

After the monthly total returns of the value and growth quintiles for each of the relative valuation benchmarks are computed, the value risk premium, proxied by the high-minus-low (HML) return difference between the value and growth quintiles is computed for each of the relative valuation benchmarks using Equation 4.

$H M L_{t}=R_{V, t}-R_{G, t}$

The value risk premium depicted in Equation 4 resembles the return generated by a zero-investment portfolio that has long position in the value portfolio and simultaneously holds short position in the growth portfolio. The historical averages of the value-growth spread calculated based on sample stocks' E/P, B/P and S/P ratios are computed and evaluated against the risk inherent in the value-growth spreads using the Sharpe ratio as demonstrated in Equation 5. 
Sharpe Ratio $_{H M L}=\left(\overline{R_{V}-R_{G}}-\overline{R_{f}}\right) / \sigma_{\left(R_{V}-R_{G}\right)}$

Where:

$\overline{\boldsymbol{R}_{\boldsymbol{V}}-\boldsymbol{R}_{\boldsymbol{G}}} \quad$ is the average monthly value-growth spread over the examination period;

$\overline{R_{f}}$

is the average monthly returns on the risk-free proxy over the examination period; and

$\sigma_{\left(R_{V}-R_{G}\right)}$

is the standard deviation of the monthly value-growth spread over the examination period.

The historical performances of the E/P, B/P and $\mathrm{S} / \mathrm{P}$ value risk premiums, represented by the respective value-growth spreads are presented in Table 2. It is evident that the average value-growth spreads are positive for all three attributes over the examination period, which indicates that value stocks on average earn higher returns compared to growth stocks on the JSE. However, the E/P spread is the only value risk premium with positive Sharpe ratio when the risk is accounted for. The E/P spread also has the highest best 12-month returns and moderate worst 12-month returns in the examination period. This result is expected as the low historical volatility of the median E/P ratio indicates that the relative valuation between value and growth stocks based on the E/P ratio is quite consistent rather than cyclical, which makes it easier for the $\mathrm{E} / \mathrm{P}$ value risk premium to accumulate over time. The pervasive performance of the E/P spread makes it a potentially good proxy for the value risk premium on the JSE. On the other hand, the average $\mathrm{B} / \mathrm{P}$ spread and $\mathrm{S} / \mathrm{P}$ spread are lower than the risk-free rate of return with significant volatility, which makes these two value-growth multiples poor proxies for the value risk premium on the JSE.

Table 2: Performance Of The E/P, B/P And S/P Value Risk Premiums (Value-Growth Spread)

\begin{tabular}{lcccc}
\hline & $\begin{array}{c}\text { Risk-Free } \\
\text { Proxy }\end{array}$ & $\begin{array}{c}\text { Earning/Price } \\
\text { Spread }\end{array}$ & $\begin{array}{c}\text { Book/Price } \\
\text { Spread }\end{array}$ & $\begin{array}{c}\text { Sales/Price } \\
\text { Spread }\end{array}$ \\
\hline Average Return & $7.41 \%$ & $8.96 \%$ & $1.59 \%$ & $5.19 \%$ \\
\hline Standard Deviation & $0.52 \%$ & $13.51 \%$ & $12.04 \%$ & $16.55 \%$ \\
\hline Sharpe Ratio & 0 & 0.115 & -0.484 & -0.134 \\
\hline Best 12 Months & $11.40 \%$ & $3.69 \%$ & $3.41 \%$ & $2.47 \%$ \\
\hline Worst 12 Months & $5.15 \%$ & $-2.37 \%$ & $-2.53 \%$ & $-2.24 \%$ \\
\hline
\end{tabular}

Observing the accumulated value of the zero-investment portfolio illustrated in Figure 1 reveals the cyclical nature of the value risk premium over the examination period. All three value-growth spreads diminished towards the market peaks before the market crash in the late 2008, but recovers quite significantly when the market eventually crashed. The value portfolios accumulated positive premiums over the growth counterparts as the European sovereign crisis emerged with the exception of the $\mathrm{B} / \mathrm{P}$ spread. The return advantage of high $\mathrm{B} / \mathrm{P}$ stocks over low B/P stocks on the JSE completely dissipates after mid-2009. The E/P and S/P value risk premiums peaked in 2012 and subdued thereafter when the concerns for the European debt crisis eased with signs of global recovery becominh more prominent. 


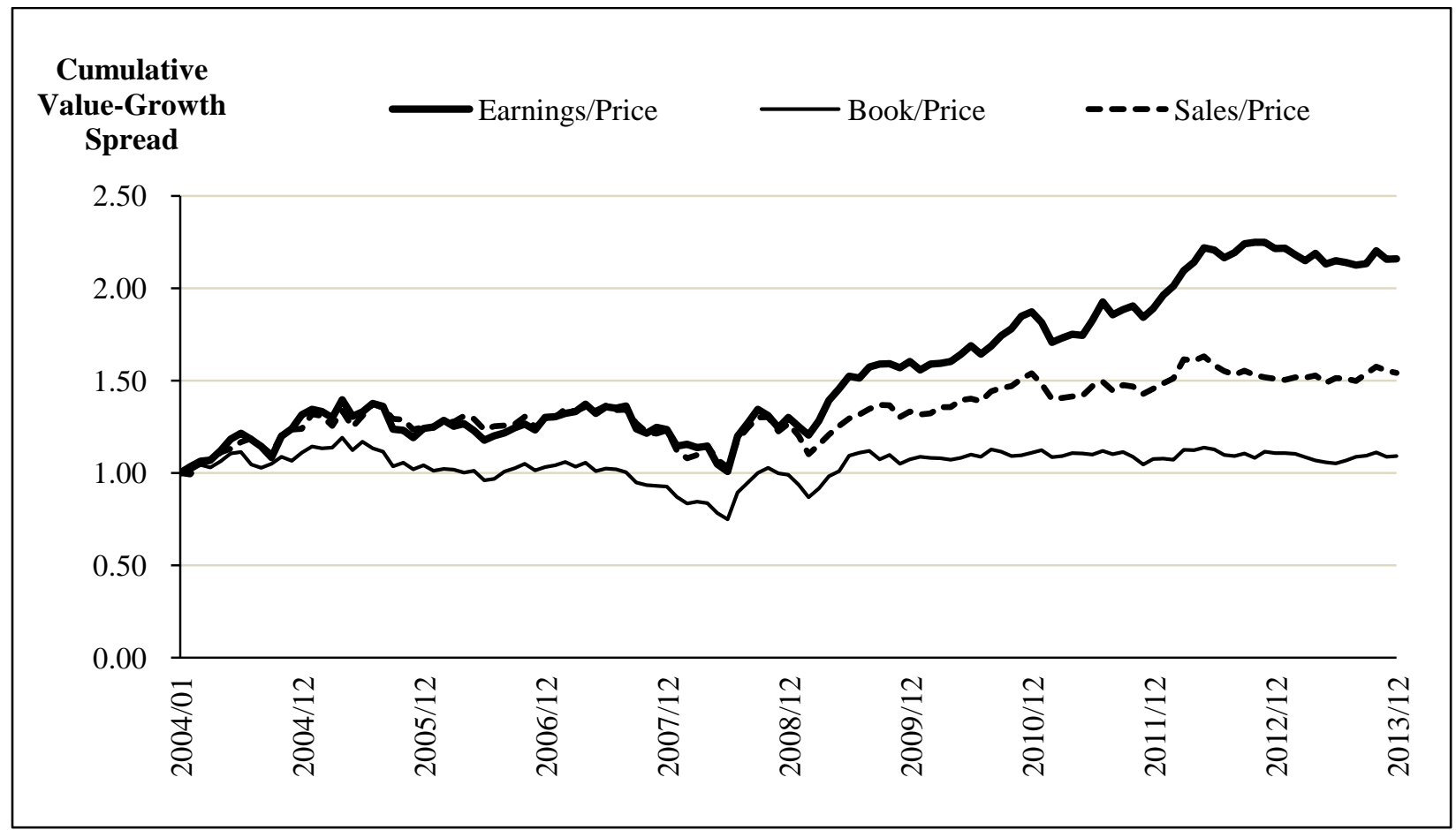

Figure 1: Cumulative Value-Growth Spread

\section{The Predictability Of Market Risk Premium Using Value-Growth Spread}

If the value risk premiums are cyclical and reflective of investor sentiments, they could be adapted to predict future market directions. This study attempts to test the predictability of the average market risk premium in the forward 12 months using the average of the trailing 12-month E/P, B/P and S/P value-growth spread. The following monthly rolling regressions are employed to predict the average market risk premium from 1 January 2005 through 31 December 2013:

${\overline{R_{m}-R_{f}}}_{t+1}=\alpha+b_{E / P} \times{\overline{H M L_{E / P}}}_{t}+\varepsilon_{t+1}$

${\overline{R_{m}-R_{f}}}_{t+1}=\alpha+b_{B / P} \times{\overline{H M L_{B / P}}}_{t}+\varepsilon_{t+1}$

${\overline{R_{m}-R_{f}}}_{t+1}=\alpha+b_{S / P} \times{\overline{H M L_{S / P}}}_{t}+\varepsilon_{t+1}$

The regression results are documented in Table 3. All three regressions are significant at the $1 \%$ level. However, the intercepts of the regressions are statistically significant, suggesting that there exists additional significant factors in explaining forward market risk premium. The coefficients for the historical value risk premiums are all significantly positive, suggesting that better rewards for equity investments are likely when recent value risk premiums are higher than average. On the other hand, compensation for investments in the equity markets are likely to diminish when the recent value risk premiums are lower than average. The coefficient of determination, $\mathrm{R}$-squared of $26.79 \%$ is the highest for the prediction using the prior S/P value risk premium. This could be due to the cyclical nature of the median S/P ratios identified earlier. When investors develop perceptions of the future market movements based on firms' recent sales, the relative performances of companies with varying sales/price multiples become a powerful tool in predicting future market directions. 
Table 3: Forecasting Forward 12-Month Market Risk Premium Using Value-Growth Spread

\begin{tabular}{|c|c|c|c|c|c|}
\hline \multirow{2}{*}{$\begin{array}{l}\text { Regression 1: } \\
\text { Intercept }(\alpha) \text { : }\end{array}$} & \multicolumn{5}{|c|}{${\overline{R_{m}}-R_{f}}_{t+1}=\alpha+b_{E / P} \times \overline{H M L}_{E / P}+\varepsilon_{t+1}$} \\
\hline & 0.0054 & Coefficient $\left(b_{E / P}\right)$ : & 0.6547 & $R$ Square: & $12.72 \%$ \\
\hline$t$-Statistic: & 2.3578 & $t$-Statistic: & 3.7213 & $F$-Statistic: & 13.8482 \\
\hline$p$-Value: & 0.0204 & $p$-Value: & 0.0003 & Significance $F$ : & 0.0003 \\
\hline \multicolumn{6}{|c|}{ Regression 2: $\quad{\overline{R_{m}-R_{f}}}_{t+1}=\alpha+b_{B / P} \times{\overline{H M L_{B / P}}}_{t}+\varepsilon_{t+1}$} \\
\hline Intercept $(\alpha)$ : & 0.0094 & Coefficient $\left(b_{B / P}\right)$ : & 0.8096 & $R$ Square: & $15.26 \%$ \\
\hline$t$-Statistic: & 5.1260 & $t$-Statistic: & 4.1360 & F-Statistic: & 17.1061 \\
\hline$p$-Value: & 0.0000 & $p$-Value: & 0.0000 & Significance $F$ : & 0.0000 \\
\hline \multicolumn{6}{|c|}{ Regression 3: $\quad{\overline{R_{m}-R_{f}}}_{t+1}=\alpha+b_{S / P} \times{\overline{H M L_{S / P}}}_{t}+\varepsilon_{t+1}$} \\
\hline Intercept $(\alpha)$ : & 0.0053 & Coefficient $\left(b_{S / P}\right)$ : & 1.2247 & $R$ Square: & $26.79 \%$ \\
\hline$t$-Statistic: & 2.7933 & $t$-Statistic: & 5.8959 & F-Statistic: & 34.7619 \\
\hline$p$-Value: & 0.0063 & $p$-Value: & 0.0000 & Significance $F$ : & 0.0000 \\
\hline
\end{tabular}

\section{CONCLUSION}

This study examines the cyclical nature of the value risk premiums proxied by the E/P, B/P and S/P valuegrowth spread over the period from 1 January 2004 through 31 December 2013. Although common cyclicality was identified for the performances of the various value-growth spread, the performance of the E/P value-growth spread is most pervasive, which makes it a good proxy for value risk premium on the JSE. The examination of the median value-growth ratios for the value portfolios versus the growth portfolios reveals that the median S/P value-growth ratios are most volatile over time, which implies that investors build in their sentiments regarding the future economic condition based on firms' recent sales, which makes the relative performance of firms with different S/P multiples a powerful tool to predict future market directions. When the historical performances of the E/P, B/P and $\mathrm{S} / \mathrm{P}$ value-growth spreads are employed to forecast the average forward 12-month market risk premium on the JSE, the S/P value-growth spread yielded the most significant R-squared of $26.79 \%$. It is also noted that the future rewards to equity investments are significantly positively correlated with the recent 12 -month E/P, B/P and S/P value risk premiums. Although all three regressions are statistically significant, the predictability of forward market risk premium could possibly be aided by including other valuation metrices such as earnings growth employed by Asness et al. (2000), which is of interest for future studies in this area. In conclusion, this study demonstrates that recent value-growth spreads are reflective of investor sentiments and degrees of risk aversion in the markets, which could be used as signals for future movements on the JSE.

\section{ACKNOWLEDGEMENTS}

I thank the research office of the University of the Western Cape for their support, and Prof. Heng-Hsing Hsieh for the preparation of research data and valuable comments.

\section{AUTHOR INFORMATION}

Professor Kathleen Hodnett teaches and supervises postgraduate Finance Research and Statistics for Investments in the School of Business and Finance at the University of the Western Cape, South Africa. She obtained a PhD from the University of Cape Town with specializations in asset pricing models, alternative investments and artificial intelligence. She is an independent consultant for Financial Statistics. E-mail: khodnett@uwa.ac.za

\section{REFERENCES}

1. Asness C. S., Friedman J. A., Krail R. J. and Liew J. M. (2000), "Style Timing: Value versus Growth", The Journal of Portfolio Management, vol. 26, no. 3, 50-60.

2. Athanassakos G. (2009), "Value versus Growth Stock Returns and the Value Premium: The Canadian Experience 1985-2005", Canadian Journal of Administrative Sciences, vol. 26, 109-121.

3. Beckers S. and Thomas J. A. (2010), "On the Persistence of Style Returns", The Journal of Portfolio 
Management, vol. 37, no. 1, 15-30.

4. Exley C. J., Smith A. D. and Wright T. (2004), Mean Reversion and Market Predictability, Stable Inn Actuary Society.

5. Fama E. F. and French K. R. (1992), “The Cross-Section of Expected Stock Returns”, Journal of Finance, vol 47, 427-465.

6. Fama E. F. and French K. R. (1993), "Common Risk Factors in the Returns on Stocks and Bonds”, Journal of Financial Economics, vol. 33, no. 1, 3-5.

7. Graham M. and Uliana E. (2001), "Evidence of a Value-Growth Phenomenon on the Johannesburg Stock Exchange", Investment Analysts Journal, no. 53, 7-18.

8. Hodnett K. E., Hsieh H. and van Rensburg P. (2012), "Payoffs to Equity Investment Styles on the JSE Securities Exchange: the Case of South African Equity Market", International Business and Economics Research Journal, vol. 11, no. 1, 19-32.

9. Kao D. and Shumaker R. D. (1999), "Equity Style Timing”, Financial Analysts Journal, vol. 55, no. 1, 37 48.

10. Lucas A., van Dijk R. and Kloek T. (2002), "Stock Selection, Style Rotation, and Risk", Journal of Empirical Finance, vol. 9, no. 1.

11. Mutooni R. and Muller C. (2007), "Equity Style Timing”, Investment Analysts Journal, no. 65, 15-24. 